\title{
Oscillation modes of humidity over the Amazon basin derived from GPS RO profiles
}

\author{
R. Hierro, ${ }^{1}$ P. Llamedo, ${ }^{1}$ A. de la Torre, ${ }^{1}$ and P. Alexander ${ }^{2}$ \\ Received 21 August 2013; revised 18 November 2013; accepted 19 November 2013; published 12 December 2013.
}

[1] The Global Positioning System radio occultation (GPS RO) technique provides vertical profiles of refractivity from which water vapor can be derived. It is possible to reproduce global, synoptic, and regional climatological patterns. From Formosa

Satellite 3/Constellation Observing System for Meteorology Ionosphere and Climate mission data (2006-2013), the variability of the moistest region of Southern Hemisphere as the Amazon basin is analyzed. Applying different spatial and temporal filters, oscillation modes of the integrated specific humidity $(Q)$ are found. A slight decreasing trend in $Q$ is found during the studied period. Zonal variability of this variable averaged in time between Amazon basin latitudes presents a main mode of oscillation of a wavelength of one quarter of the Earth (T4). A secondary mode of wavelength at around T6 wavelength is also found after high-pass filtering the original signal. In turn, temporal variability averaged over Amazon basin latitudes shows a wavelength at around 12 months, while secondary modes of 6 months are found.

Citation: Hierro, R., P. Llamedo, A. de la Torre, and P. Alexander (2013), Oscillation modes of humidity over the Amazon basin derived from GPS RO profiles, J. Geophys. Res. Atmos., 118, 13,121-13,127, doi:10.1002/2013JD020758.

\section{Introduction}

[2] The global energy transport and circulation within the Earth weather and climate system are strongly influenced by water vapor distribution through latent heat exchange. Also, it constitutes one of the most important greenhouse gases in the atmosphere. The radiative balance of the Earth surface as well as the extent and type of biosphere is largely affected by water vapor.

[3] The Amazon basin region, roughly enclosed between $0^{\circ} \mathrm{S}-20^{\circ} \mathrm{S}$ and $75^{\circ} \mathrm{W}-45^{\circ} \mathrm{W}$, constitutes the largest extent of tropical rainforest on Earth. As was pointed out by Richey et al. [2004], it provides almost $15 \%$ of the global water discharged to the oceans. Also, its influence on global climatic fields is clear, since the magnitudes of convective associated energy and precipitation. The annual mean regional precipitation becomes the most important heat source for the tropical atmosphere. Nobre et al. [2004] stated that changes in the Amazonian climate could affect the climate of other world regions through the propagation of Rossby waves emanated from the heated region. Victoria et al. [1998] found that Amazonian regional temperatures had increased at around $0.4^{\circ} \mathrm{C}$ during the twentieth century. However, they could associate this with global climate

\footnotetext{
${ }^{1}$ Facultad de Ingeniería, Universidad Austral - CONICET, Argentina.

${ }^{2}$ Instituto de Física de Buenos Aires, CONICET, Ciudad Universitaria Pabellón 1, Buenos Aires, Argentina.

Corresponding author: R. Hierro, Facultad de Ingeniería, Universidad Austral, Mariano Acosta 1901, Pilar B16290DT, Buenos Aires, Argentina. (RHierro@austral.edu.ar)

(C)2013. American Geophysical Union. All Rights Reserved. 2169-897X/13/10.1002/2013JD020758
}

change and not with local land cover changes. As was summarized by Satyamurty et al. [2012], the precipitation in the Amazon basin varies in temporal as well as in spatial domains. Marengo [2004] found a decadal variability in the region precipitation, alternating maxima between northern and the southern sectors of the basin. Later, Espinoza Villar et al. [2009] revealed a decreasing trend in this variable between 1975 and 2003, while Satyamurty et al. [2012] found that the basin average did not show any significant long-term trend.

[4] The Global Positioning System radio occultation (GPS RO) technique provides vertical profiles of atmospheric properties such as density $(\rho)$, pressure $(P)$, temperature $(T)$, and water vapor pressure $(e)$. A detailed explanation of the GPS RO techniques can be found in Kursinski et al. [1997]. This technique posses an error in $T<1 \mathrm{~K}$, operates under any weather conditions, and provides a global coverage. However, RO events occur without a regular spacing, neither in time nor in spatial resolution. GPS RO constitutes a powerful tool for atmospheric sounding which requires no calibration and is not affected by clouds, aerosols, or precipitation [Kursinski et al., 1997]. The Constellation Observing System for Meteorology Ionosphere and Climate/Formosa Satellite 3 (hereafter referred to as COSMIC) mission provides post processed profiles from near the surface to up to $40 \mathrm{~km}$, interpolated every $0.1 \mathrm{~km}$. The COSMIC mission provides approximately 1800 daily RO profiles, allowing to reproduce global, synoptic, and regional climatological patterns [Hierro et al., 2012]. The COSMIC retrievals use the "open-loop" mode tracking routine [Anthes et al., 2008], which significantly reduces the inversion biases by eliminating tracking errors [Sokolovskiy et al., 2007], extending those retrievals deeper into the lower troposphere. As was 
stated by Ho et al. [2010], in the "open-loop" mode, more than $90 \%$ of COSMIC soundings penetrate to the lowest $2 \mathrm{~km}$ of the troposphere. In order to retrieve both $e$ and $T$ profiles, the one-dimensional variational method technique [Healy and Eyre, 2000] is employed in COSMIC mission. This is an optimal way to process GPS RO, an a priori atmospheric state (European Centre for MediumRange Weather Forecasts $T, P$, and $e$ data). During the last years, several authors had analyzed the accuracy of COSMIC GPS RO humidity profiles over different regions of the world. Ho et al. [2010] analyzed the period AugustNovember 2006, comparing COSMIC water vapor with other observations and numerical simulations. They found a good agreement between them and point out the usefulness of COSMIC humidity as an independent reference for quantifying humidity uncertainties among different sensor types. The distribution of COSMIC water vapor between $50^{\circ} \mathrm{S}$ and $50^{\circ} \mathrm{N}$ was compared with radiosonde data sets by Kishore et al. [2011]. Concordance between them was verified up to $8 \mathrm{~km}$, yielding to the conclusion that water vapor data are accurate within the troposphere. Hierro et al. [2012] reproduced the tropospheric mean fields of humidity variables and pressure at different levels. They showed that this technique is able to detect the behavior of humidity at different levels both at global and at regional scales. This work is motivated by the insufficient measurements from other sources over the Southern Hemisphere, in general, and in particular over South America (SA) and the Amazon basin. The aim is to detect the main oscillation modes of the humidity over the Amazon basin, using the GPS RO technique database.

\section{Method of Analysis}

[5] Moist tropospheric air can be considered as an ideal gas composed by water vapor and dry air. Taking the ratio between the ideal gas state equation for each species, we obtain

$$
\frac{e}{P_{d}}=\frac{M_{v} R_{v}}{M_{d} R_{d}}
$$

where $e$ and $P_{d}$ are the water vapor and dry air partial pressure. $M_{v}$ and $M_{d}$ are the water vapor and dry air molar weights, respectively, and $R_{v}$ and $R_{d}$ are the respective universal gas constant. Following Salby [1996], $R^{*}=M_{v} R_{v}=$ $M_{d} R_{d}, \varepsilon=\frac{M_{v}}{M_{d}} \cong 0.622$, and $w=\frac{m_{v}}{m_{d}}$ is the mixing ratio. Thus, the relationship given by (1) can be written as follow:

$$
w=\varepsilon \frac{e}{P_{d}}
$$

Taking into account that the specific humidity is defined by $q=\frac{w}{1+w}$, from (1) and (2)

$$
q=0.622 \frac{e}{P}
$$

where $P=P d+e$ is the pressure of the moist air.

[6] COSMIC data of level 2 version "wet" vertical profiles provide temperature $(T), P$, and $e$ from near the surface up to $40 \mathrm{~km}$, interpolated every $0.1 \mathrm{~km}$. Data are binned into $1^{\circ} \times 1^{\circ}$ longitude-latitude and height cells, which are then daily averaged. Thus, $q$ is calculated as in equation (3).
[7] As a measure of the total water content, we take the integrated specific humidity $(Q)$, defined as follows:

$$
Q=-\frac{1}{g} \int_{p_{s}}^{p_{t}} q \mathrm{~d} p
$$

where $g$ is the acceleration of gravity and $P_{s}$ and $P_{t}$ are the pressure at the surface and at the top of the atmosphere, respectively. Different space and temporal scale processes are isolated, applying a nonrecursive filter which is able to retain wavelengths lower than a selected cutoff. This includes a Kaiser window [Kaiser, 1966] to minimize filtering artifacts due to the noninfinite extension of the data. Since its nonrecursive character, output does not depend on the input signal. This avoids a feedback and gives stability to the process. A well description about this tool is found in Scavuzzo et al. [1998].

[8] A useful method to detect the main oscillation modes present in a signal is the continuous wavelet transform (CWT) analysis. This technique is a powerful tool for studying multiscale and nonstationary processes occurring over finite spatial and temporal domains [Lau and Weng, 1995]. It allows to detect short-period as well as long-period oscillations. It compares the original signal against a set of synthetical ones, which are called mother wavelets, obtaining correlation coefficients. These mother wavelets, joint with a CWT and the discreet wavelet transform, define the theory of wavelets [Sang, 2013]. The comparison between signals is carried out through a process of translation and contraction or dilation of the mother wavelet [Lau and Weng, 1995] for each signal portion. This process is repeated for all scales of mother wavelet, allowing to locate short life and high-frequency signals like sharp changes, thus obtaining detailed information. In this work, the mother wavelet selected is the Morlet wavelet [Morlet, 1983], which consists of a flat wave modified by a Gaussian envelope [Lau and Weng, 1995]. This wavelet has been widely used to identify periodic oscillations of real-life signals [Labat, 2005], in the analysis of climate related records [e.g., Lau and Weng, 1995; Yi and Shu, 2012] and in several tropospheric waves studies [e.g., Llamedo et al., 2009; de la Torre et al., 2011, 2012; Hierro et al., 2013].

\section{Results}

[9] Figure 1 presents $Q$ seasonally averaged during 20062013 period. The Intertropical Convergence Zone is clearly visible around the equator, where the northeast and southeast trade winds converge in a low-pressure zone. World high-humidity zones like those dominated by the monsoon systems are also observable, such as the North American monsoon system, the African monsoon system, and the Asian monsoon system during Northern Hemisphere summer (June-August (JJA)) and the South American monsoon system and the Australian monsoon system during austral summer (December-February (DJF)). Seasonal variability of $Q$ is observable over these areas. In the Northern Hemisphere, over the Indian monsoon system the strongest contrast is found, with differences of about $15-20 \mathrm{~kg} / \mathrm{m}^{2}$ between JJA and DJF seasons. In the Southern Hemisphere, over the South American monsoon system region, $Q$ differences reach values of about $10-15 \mathrm{~kg} / \mathrm{m}^{2}$ between both 

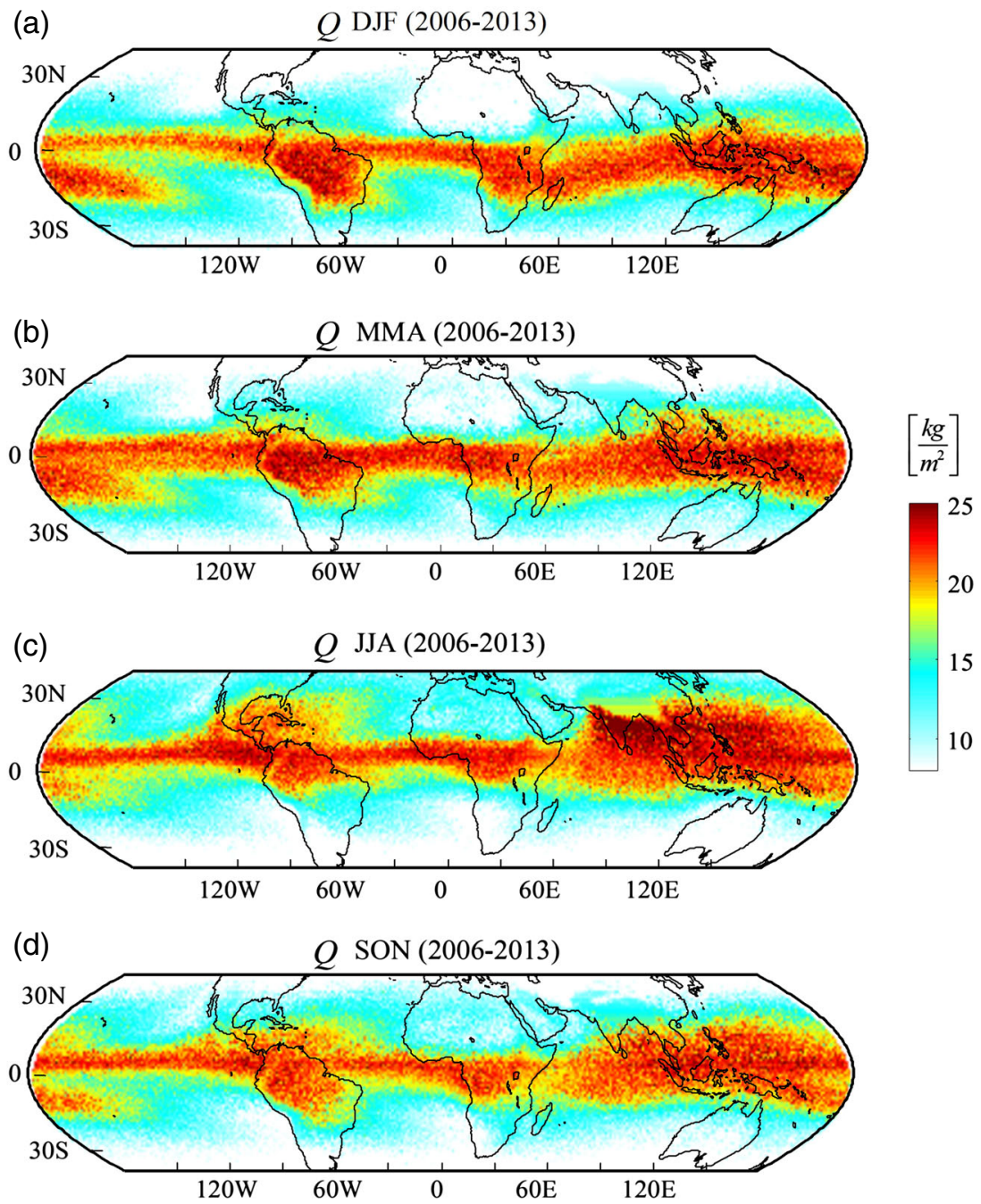

Figure 1. $Q$ derived from GPS RO COSMIC data, seasonally averaged during the period 2006-2013. (a) DJF, (b) MMA, (c) JJA, and (d) SON.

seasons. Figure 2a shows $Q$ for the Southern Hemisphere, averaged between 2006 and 2013 period $(\bar{Q})$. We define the Amazon basin region (AR) as in previous works [e.g., Satyamurty et al., 2012], within the area enclosed between $0^{\circ} \mathrm{S}-20^{\circ} \mathrm{S}$ and $75^{\circ} \mathrm{W}-45^{\circ} \mathrm{W}$ (marked on Figure $2 \mathrm{a}$, as A-B and C-D, respectively). Figure $2 \mathrm{~b}$ (top) presents the longitudinal variability of $\bar{Q}$ averaged within the latitudes A and B $\left(\bar{Q}_{\mathrm{A}_{\mathrm{B}}}\right.$, in Figure 2a). Large-scale processes seem to dominate the planetary behavior of $\bar{Q}$, with a fair peak centered at $60^{\circ} \mathrm{W}$ between the two drier zones of the hemisphere. These two minimums correspond to the west branch of the Pacific and Atlantic anticyclones (dark areas at each side of SA in Figure 2a). Along the Eastern hemisphere, the wet zones associated to West African Monsoon System (WAMS) and the Asian Monsoon System (AMS) are visible. CWT is applied to $\bar{Q}_{\mathrm{AB}}$, resulting in the correlations shown in Figure 2a (bottom). A main mode corresponding to the T4 wavelength $(\lambda)$ (of around $9 \times 10^{4} \mathrm{~km}$ ) along all longitudes for this band latitude is observable. This large-scale wave is removed by filtering $\bar{Q}$, to obtain a space-filtered signal $\bar{Q}_{\mathrm{A}_{\mathrm{B}}}^{F}$. The obtained signal is observed in Figure 2c (top), which shows the persistence of the $60^{\circ} \mathrm{W}$ maximum in accordance with the South American
Monsoon System (SAMS) location [e.g., Marengo et al., 2012, and references therein]. Removing the larger planetary processes, the WAMS is more noticeable while in turn, the AMS appears as a relative $\bar{Q}_{\mathrm{A}_{\mathrm{B}}}^{F}$ maximum between two dry zones. CWT analysis (Figure 2c, bottom) shows oscillations of $\lambda \approx 7 \times 10^{4} \mathrm{~km}$ from $120^{\circ} \mathrm{W}$ to $120^{\circ} \mathrm{E}$. Evolution of $Q$ along $100^{\circ} \mathrm{W}-10^{\circ} \mathrm{W}$ averaged between $\mathrm{A}$ and $\mathrm{B}$ bands is shown in Figure $3 \mathrm{a}$, where the vertical lines indicate February. A periodic signal of maximum values during summer is observable, between $70^{\circ} \mathrm{W}$ and $40^{\circ} \mathrm{W}$ indicates the time average of Figure $2 \mathrm{~b}$. The dry zone west of the Andes (close to $80^{\circ} \mathrm{W}$ ) is a characteristic feature of this region; since even at these latitudes, the Andes range affects the easterly flow as a barrier. A clear decreasing of averaged $Q$ is evident year to year; although taking into account the short time period considered, it could well be due to the effect of particular dry years. Similar features are observed in Hovmöller diagram between latitudes C and $\mathrm{D}$ (Figure $3 \mathrm{~b}$ ), where the decreasing $Q$ intensity with time as well as the maximum during February is evident. White lines in both figures show the latitude/longitude region enclosed by lines $\mathrm{A}, \mathrm{B}, \mathrm{C}$, and $\mathrm{D}$, hereinafter $\mathrm{AR}$. Time evolution of the resulting averaged signal enclosed 
a) $\bar{Q}\left[\frac{\mathrm{kg}}{\mathrm{m}^{2}}\right](2006-2013)$
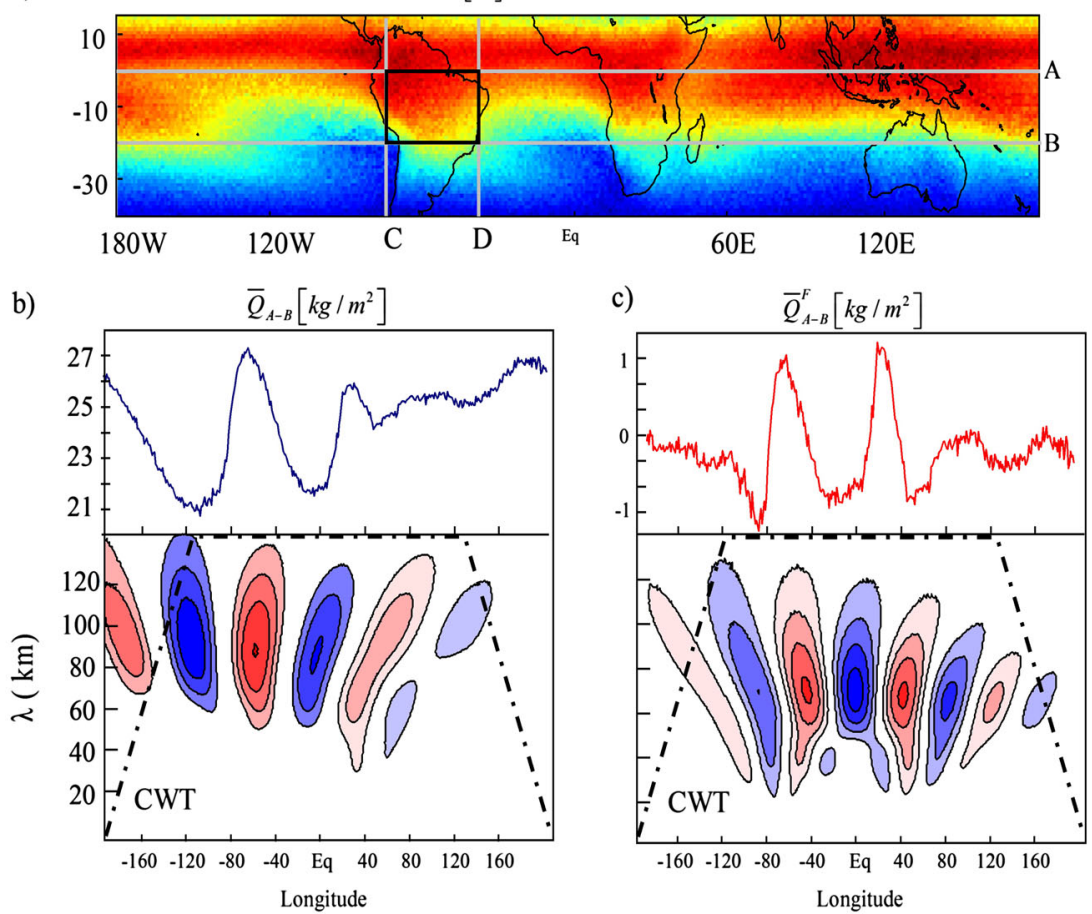

Figure 2. (a) $Q$ averaged in time $(\bar{Q}) ; \mathrm{A}, \mathrm{B}, \mathrm{C}$, and D indicate latitudes/longitudes corresponding to Amazon region (AR). (b) $\bar{Q}$ averaged between $\mathrm{A}$ and B latitudes (top) and its CWT (bottom); (c) $\bar{Q}$ filtered for waves longer than T4 $\approx 9 \times 10^{4} \mathrm{~km}$ (top) and its CWT (bottom). Dotted line in CWT indicates regions of greater than $95 \%$ confidence level.
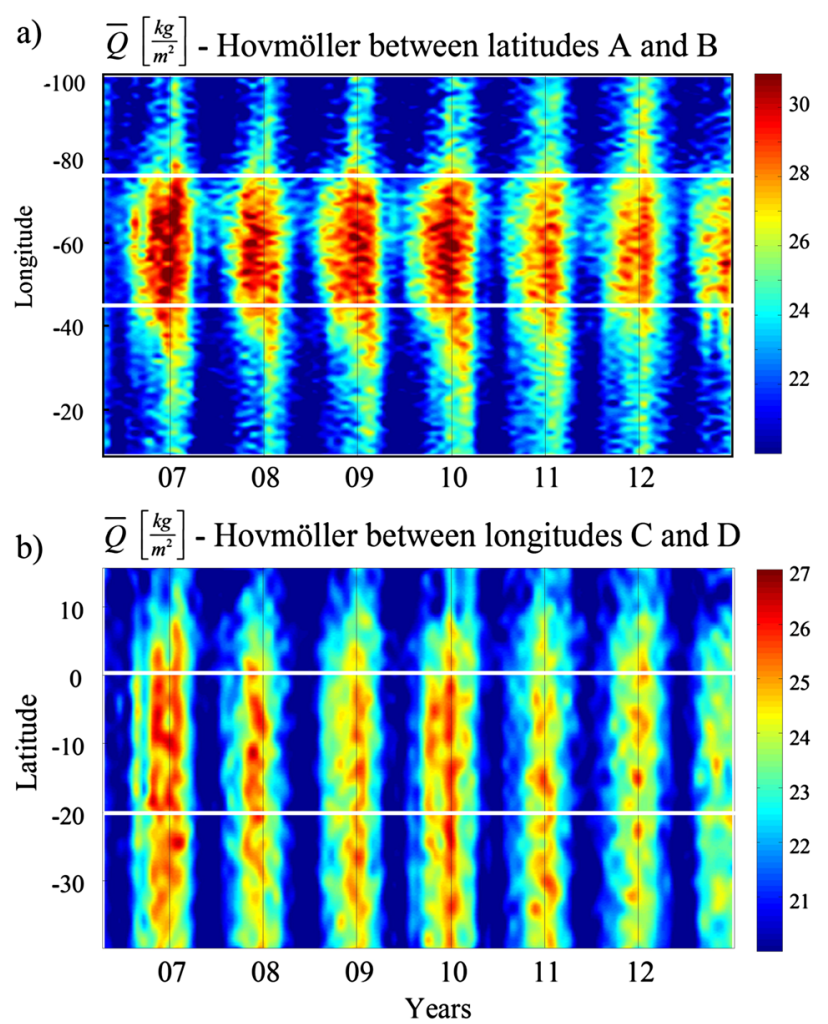

Figure 3. Hovmöller diagrams: (a) $Q$ averaged between A and $\mathrm{B}$ and $(\mathrm{b})$ averaged between $\mathrm{C}$ and $\mathrm{D}$. within $\mathrm{AR}\left(Q_{\mathrm{AR}}\right)$ is shown in Figure 4a (top). A simple linear regression analysis is applied to $Q$, considering as initial/ending points the first summer day and the last winter day of the time series, respectively. As a result, a slight trend of around $-0.325\left(\mathrm{~kg} / \mathrm{m}^{2}\right) /$ year is observed (red line) in accordance with the decreasing with time of $Q$ observed in Figures $3 \mathrm{a}$ and $3 \mathrm{~b}$. CWT analysis for $Q_{\mathrm{AR}}$ depicts, in Figure 4a (middle), an oscillation mode (M1) of temporal wavelength $\left(\lambda_{t}\right)$ at around 1 year. More detailed information about M1 is detected isolating the Morlet correlation coefficient for a period of 12 months in Figure 4 a (bottom). It shows minimum (M1-)/maximum $(\mathrm{M} 1+)$ values during April-October/November-December periods, respectively. In Figure $4 \mathrm{~b}$ (top) high frequencies modes of $Q_{\mathrm{AR}}$ are obtained, filtering $\lambda_{t}>12$ months $\left(Q_{\mathrm{AR}}^{F}\right)$. CWT analysis for this signal (Figure $4 \mathrm{~b}$ (middle)) reveals the presence of waves with periods close to 3 months (M2). The isolated Morlet correlation coefficient for a period of 5 months is presented in Figure 4b (bottom). Clearly, maximum $Q_{\mathrm{AR}}^{F}$ occurs between March and May/September and November periods (M2+), and minimum occurs between December and February/June and August periods (M2-). We represent $Q$ and $Q^{F}$ for each averaged oscillation mode in Figures $5 \mathrm{a}-5 \mathrm{f}$. Clear differences between $\mathrm{M} 1+$ and $\mathrm{M} 1-$ are observable over Amazon basin (Figures 5a and 5b). With respect to M1-, higher values of $Q$ are present in M1+ over the continental area, while over both the Atlantic and Pacific Oceans these differences are not so marked. M1+ is characterized by strong zonal land-ocean contrasts with respect to M1-. This $Q$ pattern seems to be influenced by the presence of the 

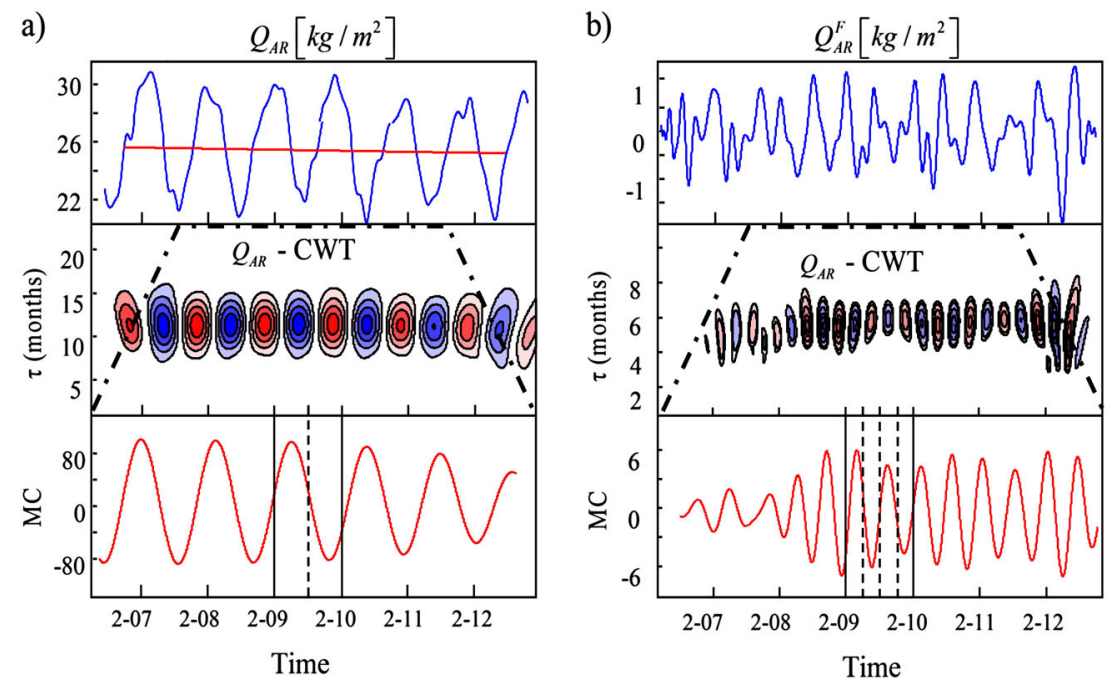

Figure 4. (a) $Q$ averaged between Amazon region $\left(Q_{\mathrm{AR}}\right)$ along time (top), its CWT (middle), and the Morlet coefficients for period between 10 and 14 months (bottom). (b) The same as 4a but for filtered $Q_{\mathrm{AR}}$ (see text) and Morlet coefficients between 4 and 6 months. Dotted dashed line in CWT indicates regions of greater than $95 \%$ confidence level. Dashed lines indicate subdivisions within 1 year.

a)

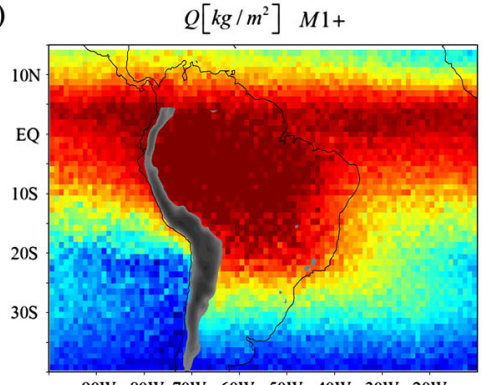

c)

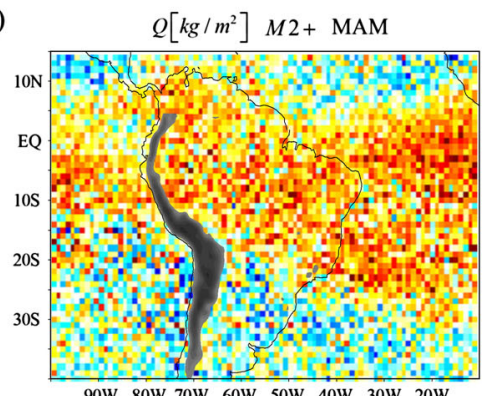

e)

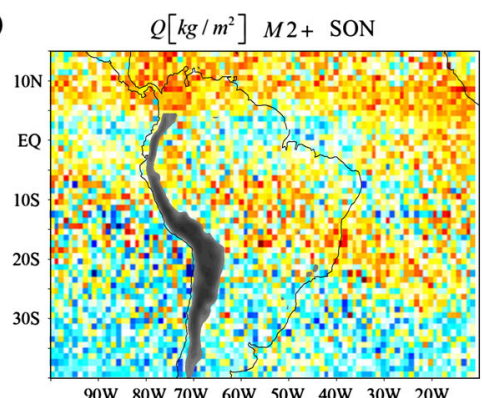

b) $\quad Q\left[\mathrm{~kg} / \mathrm{m}^{2}\right] \mathrm{M1-}$

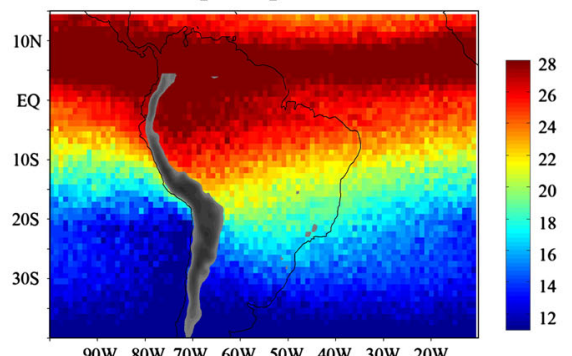

$90 \mathrm{~W} 80 \mathrm{~W} 70 \mathrm{~W} 60 \mathrm{~W} 50 \mathrm{~W} 40 \mathrm{~W} 30 \mathrm{~W} 20 \mathrm{~W}$

d)

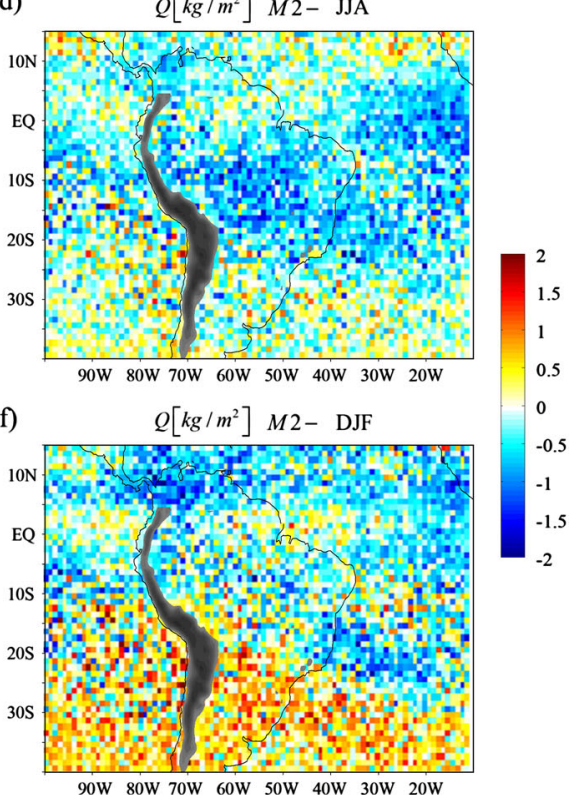

Figure 5. $Q$ averaged for (a) maximum M1 (see text), (b) minimum M1, (c) M2+ (MAM), (d) M2(JJA), (e) M2 + (SON), and (f) M2- DJF. 
semipermanent Atlantic anticyclone system, which generates dry zones over its west flank (eastern to $40^{\circ} \mathrm{W}$ in midlatitudes) and provides humidity to the Amazon basin and the northern of SA. The M1 field shows a more barotropic feature, with the maximum values of $Q$ restricted to the equator lower values over south of SA. $Q^{F}$ M2+ and M2- for March-May (MAM), June-August (JJA), September-November (SON), and December-February (DJF) are represented in Figures 5c-5f. Continental zones, in general, and AR in particular present maximum values of $Q^{F}$ during MAM (Figure 5c). Positive perturbations of $Q$ are observed between the equator and $15^{\circ} \mathrm{S}$ along the whole domain, while in southern of SA dominates $Q^{F}<0$. $Q^{F}$ within AR seems to acquire similar values than South American Convergence Zone (SACZ), which extends from NW to SE between center of SA up to $20^{\circ} \mathrm{W}$ in Figure 5c. M2- for JJA is shown in Figure 5d. Amazon basin presents negative perturbations, reaching the lower values over the continental zone. Although southern of South America is wetter, a moderate contrast between this region and $\mathrm{AR}$ is present in this mode. Although not so high as M2+ MAM, SON (M2+) field shows positive $Q^{F}$ over Amazon region. Equatorial zone, however, presents negative values. This gives place to a strong meridional contrast along the continent as well as to enhance the SACZ with respect to the other cases. Finally, DJF (M1-) seems to be the opposite case of MAM (M2+). The Amazon basin is dominated by negative perturbations, while southern of South America presents the higher values of $Q^{F}$.

\section{Conclusions}

[10] 1. Integrated specific humidity $(Q)$ averaged between Amazon region (AR) latitudes (equator to $20^{\circ} \mathrm{S}$ ) shows a main oscillation mode at around $9 \times 10^{4} \mathrm{~km}$, between longitudes $180^{\circ} \mathrm{W}$ and $80^{\circ} \mathrm{E}$. $\mathrm{AB}$ humidity is clearly observed, reaching an absolute maximum of averaged $Q$ between $80^{\circ} \mathrm{W}$ and $40^{\circ} \mathrm{W}$. This indicates that this region presents the higher water content of the Southern Hemisphere.

[11] 2. Zonal and longitudinal time evolution of $Q$ show an enhancement over $\mathrm{AB}$ as well as the decreasing with time. Hovmöller diagram (equator to $20^{\circ} \mathrm{S}$ ) presents maximum values between $80^{\circ} \mathrm{W}$ and $40^{\circ} \mathrm{W}$ centered around February. Similar features are found in a Hovmöller $\left(75^{\circ} \mathrm{W}-45^{\circ} \mathrm{W}\right)$, with a maximum between equator and $25^{\circ} \mathrm{S}$ and a decreasing with time.

[12] 3. Time evolution of the resulting averaged signal enclosed within $\mathrm{AB}\left(Q_{\mathrm{AR}}\right)$ shows a slight decreasing trend present, in accordance with Hovmölle diagrams. An oscillation mode of 1 year (M1) is found applying a CWT analysis. From this technique, minimum/maximum values during April-October/November-December periods are found, respectively.

[13] 4. Averaged fields of M1+ and M1- depict higher values of $Q$ in $\mathrm{M} 1+$ with respect to $\mathrm{M} 1$ - over the continent, as well as strong zonal land-ocean contrasts. The M1-field shows a more barotropic feature, with the maximum values of $Q$ restricted to the equator lower values over south of South America.

[14] 5. Filtering $Q_{\mathrm{AR}}$ signal for $\lambda_{t}>12$ months $\left(Q^{F}\right)$, waves with periods close to 3 months are obtained (M2). For this higher frequencies modes, maximum occurs between MAM and SON periods (M2+) and minimum occurs between DJF and JJA periods (M2-).

[15] 6. M2+ for MAM presents the higher values of $Q^{F}$ over Amazon basin (AR), while in Southern of SA dominates $Q^{F}<0$. The SACZ seems to be present in this mode. In turn, $\mathrm{M} 2+(\mathrm{SON})$ shows also positive $Q^{F}$ over AR, however, lower than those observed during MAM. The AR humidity seems to be provided mainly by the SACZ activity, yielding to a meridional contrast of $Q^{F}$.

[16] 7. The more negative values of $Q^{F}$ over $\mathrm{AR}$ are obtained during JJA (M2-). However, over the continental zone, the meridional contrasts are lower than in other cases. Finally, DJF (M1-) seems to be the opposite case of MAM $(\mathrm{M} 2+)$. The Amazon basin is dominated by negative perturbations, while southern of South America presents the higher values of $Q^{F}$.

[17] Acknowledgments. This paper was prepared under grant CONICET PIP 0649. R. Hierro, P. Llamedo, A. de la Torre and P. Alexander are members of CONICET. We acknowledge COSMIC data provided by UCAR and the data center CDAAC (http://cdaac-www.cosmic.ucar.edu/ cdaac/index.html).

\section{References}

Anthes, R. A., D. Ector, D. C. Hunt, Y.-H. Kuo, C. Rocken, W. S. Schreiner, S. V. Sokolovskiy, S. Syndergaard, T.-K. Wee, and Z. Zeng (2008), The COSMIC/FORMOSAT-3 mission: Early results, Bull. Am. Meteorol. Soc., 89, 313-333, doi:10.1175/BAMS-89-3-313.

de la Torre, A., R. Hierro, P. Llamedo, A. Rolla, and P. Alexander (2011), Severe hailstorms near southern Andes in the presence of mountain waves, Atmos. Res., 101(1-2), 112-123, doi:10.1016/j.atmosres. 2011.01.015.

de la Torre, A., P. Alexander, R. Hierro, P. Llamedo, A. Rolla, T. Schmidt, and J. Wickert (2012), Large-amplitude gravity waves above the southern Andes, the Drake Passage, and the Antarctic Peninsula, J. Geophys. Res., 117, D02106, doi:10.1029/2011JD016377.

Espinoza Villar, J. C., J. Ronchail, J. L. Ouyot, G. Cochonneau, F. Nazianao, W. Lavado, E. De Oliveira, R. Pombosa, and P. Vouchel (2009), Stationtemporal rainfall variability in the Amazon basin countries (Brazil, Peru, Bolivia, Colombia and Equador), Int. J. Climatol, 29, 1574-1594, doi:10.1002/joc.1791.

Healy, S. B., and J. R. Eyre (2000), Retrieving temperature, water vapour and surface pressure information from refractive-index profiles derived by radio occultation data: A simulation study, Q.J. R. Meteorol. Soc., $126,1661-1683$

Hierro, R., P. Llamedo, A. de la Torre, P. Alexander, and A. Rolla (2012), Climatological patterns over South America derived from COSMIC radio occultation data, J. Geophys. Res., 117, D03116, doi:10.1029/2011JD016413.

Hierro, R., H. Pessano, P. Llamedo, A. de la Torre, P. Alexander, and A. Odiard (2013), Orographic effects related to deep convection events over the Andes region, Atmos. Res., 120-121, 216-225, doi:10.1016/j.atmosres.2012.08.020.

Ho, S.-P., X. Zhou, Y.-H. Kuo, D. Hunt, and J.-H. Wang (2010), Global evaluation of radiosonde water vapor systematic biases using GPS radio occultation from COSMIC and ECMWF analysis, Remote Sens., 2, 1320-1330, doi:10.3390/rs2051320.

Kaiser, J. F. (1966), Digital filters, in System Analysis by Digital Computer, chap. 7, edited by F. F. Kuo and J. F. Kaiser, Wiley, New York.

Kishore, P., M. V. Ratnam, S. P. Namboothiri, I. Velicogna, G. Basha, J. H. Jiang, K. Igarashi, S. V. B. Rao, and V. Sivakumar (2011), Global $\left(5^{\circ} \mathrm{S}-5^{\circ} \mathrm{N}\right)$ distribution of water vapor observed by COSMIC GPS RO: Comparison with GPS radiosonde, NCEP, ERA-Interim, and JRA-25 reanalysis data sets, J. Atmos. Sol. Terr. Phys., 73, 1849-1860, doi:10.1016/j.jastp.2011.04.017.

Kursinski, E. R., G. A. Hajj, J. T. Schofield, R. P. Linfield, and K. R. Hardy (1997), Observing Earth's atmosphere with radio occultation measurements using the Global Positioning System, J. Geophys. Res., 102, $429-465$.

Labat, D. (2005), Recent advances in wavelet analyses: Part 1. A review of concepts, J. Hydrol., 314, 275-288. 
Lau, K.-M., and H. Weng (1995), Climate signal detection using wavelet transform: How to make a time series sing, Bull. Am. Meteorol. Soc., 76, 2391-2402.

Llamedo, P., A. de la Torre, P. Alexander, D. Luna, T. Schmidt, and J. Wickert (2009), A gravity wave analysis near to the Andes range from GPS radio occultation data and mesoscale numerical simulations: Two case studies, Adv. Space Res., 44(4), 494-500.

Marengo, J. (2004), Interdecadal variability and trends of rainfall across the Amazon basin, Theor. Appl. Climatol., 78, 79-96, doi:10.1007/s00704004-0045-8

Marengo, J. A., et al. (2012), Recent developments on the South American monsoon system, Int. J. Climatol., 32, 1-21, doi:10.1002/joc.2254.

Morlet, J. (1983), Sampling theory and wave propagation, in Acoustic Signal/Image Processing and 502 Recognition, in NATO ASI, vol. 1, edited by C. Chen, pp. 233-261, Springer-Verlag, New York.

Nobre, C., M. Silva Dias, M. Culf, D. Alistair, J. Polcher, J. Gash, J. Marengo, and R. Avissar (2004), The Amazonian climate, in Vegetation, Water, Humans and the Climate, 1st ed., vol. 1, edited by P. Kabat et al., pp. 99-118, Springer, Londres.

Richey, J., E. Victoria, E. Mayorga, L. Martinelli, and R. Meade (2004), Integrated analysis in a humid tropical region-The Amazon basin, in Vegetation, Water, Humans, and the Climate, edited by P. Kabat, pp. 415-418, Springer-Verlag, Berlin Heidelberg.
Salby, M. L. (1996), Fundamentals of Atmospheric Physics, vol. 61 of International Geophysics Series, Academic Press, San Diego, Calif.

Sang, Y.-F. (2013), A review on the applications of wavelet transform in hydrology time series analysis, Atmos. Res., 122, 8-15, doi:10.1016/j.atmosres.2012.11.003.

Satyamurty, P., C. P. Wanzeler da Costa, and A. O. Manzi (2012), Moisture source for the Amazon basin: A study of contrasting years, Theor. Appl. Climatol., 1, 195-209.

Scavuzzo, C. M., et al. (1998), A study of the low-frequency inertio-gravity waves observed during the Pyrnes Experiment, J. Geophys. Res., 103, 1747-1758.

Sokolovskiy, S. V., C. Rocken, D. H. Lenschow, Y.-H. Kuo, R. A. Anthes, W. S. Schreiner, and D. C. Hunt (2007), Observing the moist troposphere with radio occultation signals from COSMIC, Geophys. Res. Lett., 34 , L18802, doi:10.1029/2007GL030458.

Victoria, R., L. Matinelli, J. Moraes, M. Ballester, A. Krusche, G. Pellegrino, R. Almeida, and J. Richey (1998), Surface air temperature variations in the Amazon region and its borders during this century, J. Clim., 11, 1105-1110.

Yi, H., and H. Shu (2012), The improvement of the Morlet wavelet for multi-period analysis of climate data, C. R. Geosci., 344(10), 483-497, doi:10.1016/j.crte.2012.09.007. 